$10-2019$

\title{
Longitudinal Relationships Between Parent Factors, Children's Bullying, and Victimization Behaviors
}

Esther K. Malm

Murray State University, emalm@murraystate.edu

Christopher C. Henrich

Georgia State University

Follow this and additional works at: https://digitalcommons.murraystate.edu/faculty

Part of the Child Psychology Commons

\section{Recommended Citation}

This is a pre-print of an article published in Volume 50, Issue 5 of Child Psychiatry \& Human Development. The final authenticated version is available online at: https://doi.org/10.1007/s10578-019-00882-9

This Peer Reviewed/Refereed Publication is brought to you for free and open access by Murray State's Digital Commons. It has been accepted for inclusion in Faculty \& Staff Research and Creative Activity by an authorized administrator of Murray State's Digital Commons. For more information,

please contact msu.digitalcommons@murraystate.edu. 
Running Head: PARENT FACTORS, BULLYING \& PEER VICTIMIZATION

Longitudinal Relationships Between Parent Factors, Children's Bullying, And Victimization Behaviors.

\author{
Esther K Malm, PhD \\ Murray State University \\ Christopher C. Henrich, PhD \\ Georgia State University
}

*Corresponding Author: Esther K. Malm, PhD; Murray State University, Department of Psychology, 212 Wells Hall, Murray, KY 42071; Email: emalm@ murraystate.edu 


\begin{abstract}
Longitudinal data from NICHD Study of Early Child Care and Youth Development tested direct, indirect and reciprocal effects of maternal depressive symptoms, stress/support factors on child bullying and peer victimization through mother-child relationship quality at grades 3, 5, 6. Data from 828 mothers-child dyads indicated small significant effects of some hypothesized pathways, including a small direct effect of maternal depressive symptoms at grade 3 on peer victimization at grade 5, but not on bullying behaviors. Mother-child relationship quality at grade 5 negatively predicted bullying at grade 6 , but not peer victimization. There were small effects of bullying behaviors at grade 5 on decreased mother-child relationship quality at grade 6. Maternal employment at grade 3 predicted decreased bullying behaviors at grade 6 through mother-child relationship quality at grade 5. Findings are relevant for parent inclusive research and approaches to anti-bully intervention strategies and prevention policies.
\end{abstract}

INDEX WORDS: Bullying, Peer Victimization, Parent factors, Maternal Depressive symptoms, Parental Stress and Support Factors 


\section{Longitudinal Relationships Between Parent Factors, Children's Bullying And Victimization Behaviors.}

Recent longitudinal studies have reported associations between childhood experiences of bullying behaviors and peer victimization, and poor mental and social health in young adulthood [1-4]. Although there are mixed reports on the national prevalence of bullying and peer victimization among school going children [5-8], the most current national survey on peer victimization reported approximately $8 \%$ decline between 2009 and 2015 school year [6,9] However, the debilitating effects of bullying and peer victimization on the emotional, social and mental health of individuals continue to persist long term into adulthood [1]. To date, there has been limited research related to the roles parents play in children's engagement in bullying and experiences of peer victimization (bullying and peer victimization) [11, 12] Since families typically display recurring patterns of both adaptive and maladaptive interactive behaviors and are the primary modeling agents for their children $[12,13]$, it is important to evaluate the family context and in the development, maintenance and reduction of bullying and victimization behaviors in their children [14].

Parent factors are many and broad, however, frameworks such as the parenting process model [15] and developmental psychological theories (e.g., transactional and bio-ecological models) $[13,16]$ acknowledge both the interrelated nature of types of parent factors as well as explain how these family contexts influence adaptive and maladaptive behaviors directly, indirectly and in transactional patterns over time. Based on both frameworks, we are interested in understanding how mother-child relationship quality (parenting), maternal depression (parent functioning) and stress and support variables influence peer victimization and bullying behaviors over time.

\section{Maternal Depressive symptoms, Parenting, Bullying and Victimization Behaviors}


Extant studies on maternal depression have documented its detrimental impact on various physical, behavioral, socio-emotional behaviors and academic difficulties in children across all developmental stages [17-24]. Researchers have also begun to examine the possible relationship between maternal depressive symptoms, bullying and victimization behaviors, finding substantial associations, which warrant further research. For example, a cross-sectional study of the correlates between maternal depressive symptoms, bullying and victimization in a Greek sample within a school district by Georgiou [25], for example, revealed that maternal depressive symptoms predicted more bullying behaviors and peer victimization among elementary school students. While the study indicated important associations between maternal depressive symptoms, bullying and peer victimization, our research seeks to examine these relationships in a comprehensive longitudinal sample.

The quality of maternal -child relationships has also been known to be important in understanding transactional relationships, particularly as a mediator of the relationship between maternal depression and child maladjustments [20]. Earlier and current studies have consistently shown that mothers with clinical depression compared to non-clinically depressed mothers are more likely to provide a rejecting home environment, show less emotional and instrumental support, communication, warmth, and have lower self-efficacy in their abilities to parent [15, 2630]. Additionally, mothers with depression tend to have poor parenting and negative cognitions of self that their children may eventually model [31].

Parent -child conflict, and support quality in particular, has been extensively studied among parents and adolescents [32], most likely because this is the developmental phase where teenagers learn to bid for autonomy and independence. In a longitudinal study that examined the associations between parent depressive symptoms and parent-adolescent relationship (conflict and support) among teenagers who had a high risk of dropping out of school, Kim et al. [33], 
found that parental depression significantly predicted adolescents' low perceptions of parental social support over time, beyond other child risk factors. Furthermore, low parent-adolescent conflict was associated with lower child depression rates and hopelessness over time.

Extrapolating such findings to the field of bullying and peer victimization, there is the possibility that the putative link between maternal depressive symptoms, bullying and victimization behaviors, if any, may not only be through the choice of parenting practices per se, but more importantly through the quality of parent-child relationship that exists. There is however limited studies exploring these links and hence a focus of this study.

The debilitating effects of maternal depressive symptoms do not occur in a vacuum. Different stress and support factors significantly influence both parent functioning and parenting [15]. From Belsky's parenting process model [15] and more recent empirical studies, three main sources of stress and support that are likely to promote or undermine parental functioning and parenting are marital /partner relationships [34-36], social networks [37, 38], and employment status $[39,40]$. Besides the few studies on marital/partner conflict and domestic violence, which have reported associations with bullying and victimization behaviors [41, 42], little is known about the longitudinal effects of these particular parent stress and support factors on maternal depressive symptoms, parent-relationship quality and subsequently bullying and victimization behaviors in children.

Lastly, from transactional longitudinal investigations, there is evidence that children's behaviors and functioning have significant effects on parents too $[43,44]$. In a study that looked at the effects of disruptive aggressive behaviors in male children on rates of depressive symptoms in their mothers over time, Gross et al. [45], found significant positive and reciprocal effects of boys' disruptive behaviors and maternal depressive symptoms on each other at a later time. In studies that examined the relationships between maternal involvement [46], mother- 
child relationships (i.e., closeness and conflict) [47], and bullying/victimization behaviors over time, the authors found significant reciprocal effects, in that, maternal involvement reduced the likelihood of bullying behaviors overtime, while bullying behaviors was associated with lower maternal involvement over time [46]. In addition, positive parent-child relationships were associated with lower reports of bullying behaviors over time, and for boys in particular [47]. In summary, these studies, suggest that the effects of maternal depressive symptoms can be associated with child functioning and behaviors (bullying and victimization) through direct, bidirectional and indirect pathways.

\section{Research Goals and Hypotheses}

The aim of the present study was to examine the transactional effects of maternal depressive symptoms on engagement in bullying and experiences of peer victimization among children at grades 3,5 and 6 , as potentially mediated through mother-child relationship quality. Acknowledging that parent stress/support factors influence parent functioning and parenting, we first hypothesized that marital intimacy, employment status and perceived social support would negatively predict maternal depressive symptoms but positively predict mother-child relationship quality over time. Secondly, maternal reports of depressive symptoms would directly and positively predict engagement in bullying and experiences of peer victimization over time, and indirectly through mother-child relationship quality. Lastly, we hypothesized that effects would be bidirectional, that is, engagement in bullying and experiences of peer victimization would negatively predict mother-child relationship quality and maternal reports of depressive symptoms over time.

\section{Method}

\section{Participants and Procedure}


Data for this study were from the longitudinal dataset of the National Institutes of Child Health and Development (NICHD) study of Early Child Care and Youth Development (SECCYD) [48]. The SECCYD study followed 1364 children and their parents from birth (in 1991) until age 15. Participants were from ten US cities across the country and economically diverse. Examples of inclusion criteria for the original study include being age 18 or older, could speak English, was not planning to move or adopt child, no known substance abuse history [48]. For this study, adolescent and maternal data $(\mathrm{N}=1072)$ from 3rd, 5th and 6th grade students were selected, because they were the only grades at which bullying and victimization behaviors were assessed in students. Mothers gave self-reports on marital intimacy, social support, parenting styles, parent-child relationship, work status and other demography while adolescents gave selfreports on their bullying and victimization behaviors at grades 3, 5 and 6. Of the 1072 mother child dyads, 828 mothers reported being married or living with a partner and, responded to the marital intimacy/satisfaction questions. Therefore, the final analyses were based on 828 dyads in order to accurately examine the role of this hypothesized parent factor in the milieu of developmental transactions. Parent and child demographics of the study sample are summarized

in Table 1. Almost twenty-nine prevent $(28.5 \%)$ of the mothers in the study sample had no more than a high school education at recruitment, $16 \%$ were ethnic minorities and about $80 \%$ of mothers were married/partnered at grades 3,5 and 6. For the children, $50 \%$ of them were male, $18 \%$ of them were ethnic minorities. Authors' Institutional Review Board approved this study.

\section{Instruments}

The Center for Epidemiologic Studies, Depression Scale [CES-D] [49]. Mothers' depressive symptoms were measured by the CES-D at grades 3, 5 and 6 of their children. The CES-D comprises 20 items that assess depressive symptoms experienced during the week prior 
to the evaluation. Examples of items are "I could not get going" and "I did not feel like eating; my appetite was poor."

From the NICHD dataset, Cronbach alphas for CES-D (mothers) were .91, .90 and .91 at grades 3, 5 and 6 respectively [48]. Item responses ranged from 1 (less than once a week) to 4 (57 days a week). Total scores ranged from 1-60 with higher total scores signifying more depressive symptoms [48]. The clinical cut off for the 20 item scale is 16, indicating "mild" or "significant" symptomatology $[49,50]$. In the current study however, the mean CES-D score across the three grades were $9.08,8.73$ and 8.96 respectively. The median score was 6.00 for each grades.

Child - Parent Relationship Scale [Short form; CPRS] [51]. This 15-item parent questionnaire probed parents' feelings and beliefs about their relationship with the study child and about the child's behavior toward the parent. The NICHD study evaluated three sub-areas: Conflict with child, closeness with child and total positive relationship with child. Items that assessed conflict include "My child and I seem to be struggling with each other," while closeness was assessed with items including "My child values his/her relationship with me [51]." Our study used the total positive relationship score, which was the sum of scores on both scales.

The NICHD study reported internal consistency and validity rates by grades. For grades 3, 5 and 6, the reliability coefficients for total positive relationships with child ranged from .81 , .82 and .84 respectively [48]. The measure had moderate correlations with behavioral ratings including Social Skills Rating System and Child Behavior Checklist [48, 51].

Parents rated items on a 5-point Likert scale from 1 (Definitely does not apply) to 5 (definitely applies). Scores were computed as the sum of the 15 with items $2,4,8,10,11,12,13$, and 14 being reverse coded. The possible range of scores was $15-75$, with higher scores 
indicating more positive total relationships between the mother and child [48]. The mean scores for our study across the three grades were 63.06, 62.19 and 61.41 respectively.

Personal Assessment of Intimate Relations [52]. The Personal Assessment of Intimacy in Relationships (PAIR) is originally a 36-item instrument designed to assess the quality and characteristics of marital or partner relationships. All levels of dyadic heterosexual relationships from friendship to marriage could be evaluated through this self-report inventory. The PAIR measures the expected versus the realized degree in five areas of intimacy: emotional intimacy, social intimacy, sexual intimacy, intellectual intimacy, and recreational intimacy. For the NICHD study, only the emotional intimacy subscale (Love and Relationship scale) was used, which comprises of six items.

The emotional intimacy subscale was internally consistent $(\alpha=0.70)[48,53]$. Scores ranged from 1 (strongly disagree) to 5 (strongly agree) on a Likert scale. Scores were calculated as the mean of the responses to the six items, with higher scores indicating better partner relations. For our study, the mean maternal scores across grades 3, 5 and 6 were 3.88, 3.86 and 3.83 respectively.

Maternal Social Support: This questionnaire was designed by the NICHD study team to measure parent's perception of the support or assistance others provided over the past month (i.e., spouse/partner, children, family or other important people in their life [48]. It was measure at only Grades 3 and 5. The 11 questions focused on functions of social relationships (i.e., sharing concerns, intimacy, and opportunities for nurturance, reassurance of worth, and assistance/guidance). The measure had a high level of internal consistency (Cronbach's alpha = $.91)$ with a test-retest internal consistency score of .68 over 4 months [48].

Responses were on a 6- point Likert scale ranging from 1 (None of the time) to 6 (All of the time). The Total Social Support score was rated as the mean of responses to the 11 items, 
which was computed using proportional weighting. Higher scores indicated higher perceptions of social support during the last month. For our study, the mean score of total social support perceived by mothers was 5.12 and 5.11 for grades 3 and 5 respectively.

Maternal Employment Status (Grades 3, 5, 6): This interview was also developed for the NICHD study [48] to collect specific information from all mothers using a systematic form and objective technique. Employment status was coded as 0 (unemployed) and 1 (employed, on vacation, on leave). From Table 1, more mothers were employed across the three time points ( $M$ $=.76)$.

Engagement in Bullying \& Experiences of Peer Victimization Scale: This measure (entitled in the NICHD data as Peer Social Support, Bullying, \& Victimization) was a compilation of 18 items taken from three questionnaires developed by Ladd and his colleagues [54]. The scale measured engagement in physical and verbal bullying behaviors with school classmates, and perceived victimization at grades 3, 5 and 6. Moderate internal consistency was reported for victimization (4 items, Cronbach's alpha $=.81)$ and bullying behaviors (4 items, Cronbach's alpha $=.78)$.

These items assessed physical, verbal and relational bullying and victimization. The bullying behavior items were: Do you (a) pick on other kids in your class at school, (b) say mean things to other kids in your class, (c) say bad things about other kids in your class at school, and (d) hit other kids in your class at school? Similarly, questions assessing victimization were: Does anyone in your class (a) pick on you at school, (b) say mean things to you at school, (c) say bad things about you to other kids at school, and (d) hit you at school?

Responses were rated on a 5 point Likert scale, from 1 (Never) to 5 (Always). Scoring for perceived victimization was computed as the average of the responses to the four victimization items, while Engagement in bullying behaviors score was computed as the average of the 
responses to the four bully items. Higher scores on the bullying and victimization scales indicated higher reports of engagement in bullying, and higher rates of perceived victimization respectively. Across the three grades, mean perceived victimization scores ranged between 1.76 and 1.84 while bully scores ranged between 1.21 and 1.37 .

Covariates. Three parent variables were included as covariates in all the models. The parent covariates were (1) maternal ethnicity, with Caucasian and others as the comparison group to African American, and (2) maternal income at grade three. Maternal income and marital status was selected at grade 3 because these variables had high correlations with mother's marital status at grades 5 and 6. Child temperament was also included as covariates in all the models. Studies examining temperament and bullying behaviors acknowledge anger and fear as two temperamental traits associated with bullying and peer victimization respectively [55], therefore anger and fear were considered. However, only the anger trait was included in the study because the fear variable was not significantly correlated with bullying or victimization behaviors at the three grades. By controlling for it, we sought to examine the role of parent factors on bullying behaviors, above and beyond child temperament.

Children's temperament was measured once in the NICHD study when children were 54 months old using the Children's Behavior Questionnaire [56] The Cronbach's alpha for the anger subscale was .60-.85 [48]. Each trait was measure by a 10-item subscale using a 7-point Likertstyle scale $(1=$ extremely untrue and $7=$ extremely true of your child $)$. Scores were computed as the mean of items for each dimension with higher scores indicative of a higher level of anger or being easily angered when interrupted from ongoing tasks or goal blocking.

\section{Results}

\section{Statistical Analytic Design}


A three-wave cross-lagged structural equation model examined the hypotheses. Cross-lagged models examine predictive associations between variables over time, while controlling for effects at earlier time points. They also give information about changes in effect of variables over time [57]. All analyses were done using the Mplus software, v7 [58]. Outcome variablesengagement in bullying and experiences of peer victimization - were estimated simultaneously in all models. All covariates (maternal ethnicity, income, marital status at grade 3 , and child temperament at 54 months) were also included in all the models where all the predictors in grade 3 were regressed on these covariates.

The hypothesized structural paths were estimated across the three time points. Within each wave, correlations of all variables were estimated. For clarity of figures in the results section, all correlations in the model are reported in Table 2, while within wave correlations for the final model are shown in Table 3. Model fit was assessed by evaluating a number of fit indices. Four fit indices are reported. Root Mean Square Error of Approximation (RMSEA) compares the estimated model to the population covariance matrix [59]. RMSEA values range from 0.00-1.00. Values $\leq 0.05$ suggest a good fitting model. Comparative fit Index (CFI) compares estimated model to the baseline model. CFI values range from 0-1.0 where 1.0 indicates best fit [59]. Standardized Root Mean Square Residual (SRMR) indicates the overall difference between the observed and predicted correlations. Values $\leq .05$ suggest good fit with 0 indicating best fit.

\section{Missing Data}

All predictors in the hypothesized model had less than $8 \%$ missing data. To ensure minimal bias in data, all analyses were run using results averaged from 30 random multiple imputation datasets that was generated from the original dataset $(\mathrm{N}=1072)$ in Mplus. The multiple imputation technique is a method, which uses Bayesian analyses to estimate missing data where 
missing values on more than one variable are simultaneously generated from other predictors [60]. Maximum likelihood with robust estimation (MLR) was used in the analyses.

\section{Descriptive statistics}

Table 2 shows correlations of all the variables used. All the variables were screened to examine their distribution. From Table 2, significant correlations between the covariates, bullying and peer victimization variables ranged between -0.07 and 0.18 across the three grades. For predictors, significant correlations between the maternal depressive symptoms and parent child relationship quality across the three grades ranged between -0.24 and -0.30 . Also, significant correlations between the maternal depressive symptoms, bullying and peer victimization variables across the three grades ranged from 0.07 to 0.17 . The strongest significant correlations were negative correlations between maternal depressive symptoms and marital intimacy across the three grades and ranged between -0.27 to -0.43 . Examination of the child variables showed that bullying variables were significantly correlated across time points, and ranged between .17 and .55 . Similarly, victimization behaviors at across the 3 grades were significantly correlated and ranged between .12 and .55. Correlations between bullying and peer victimization behaviors were also significant and ranged between 0.50 and 0.99 across the three time points.

\section{Structural Model Results}

Two cross-lagged models were estimated. The baseline model A (Figure 1) was specified to estimate direct and indirect effects of the three stress and support factors on maternal reports of depressive symptoms parent-relationship quality (hypothesis 1), maternal reports of depressive symptoms on bullying and peer victimization through parent-relationship quality (Hypotheses 2 and 3), as well as, hypothesized bidirectional effects (hypothesis 4). In building the model, maternal depressive symptoms and mother-child relationship quality at grades 5 and 6 were 
regressed on stress and protective factors (marital intimacy, social support and employment status) at grade 3 and 5 respectively. Bullying and peer victimization at grade 5 and 6 were also regressed on maternal depressive symptoms and mother-child relationship quality at grades 3 and 5 respectively. To test the bidirectional effects, maternal depressive symptoms and mother-child relationship quality at grades 5 and 6 were regressed on bullying and peer victimization at grades 3 and 5 respectively. All parent and child grade 3 variables were regressed on the covariates in both models.

Fit statistics for Model A $\left(\chi^{2}=213.89, d f=115, \mathrm{RMSEA}=.03 ; \mathrm{CFI}=.98 ; \mathrm{SRMR}=.03, \mathrm{AIC}\right.$ $=49760.55)$ indicated that there were other important cross-lagged paths not estimated in the hypothesized model. As a result, a second model (B) was estimated in which, paths between parent and child variables not hypothesized in the study were estimated. Specifically, reciprocal paths between the three stress and protective factors, between maternal depressive symptoms and mother-child relationship quality, and between bullying and peer victimization were estimated across time.

Results showed that model B best fit the data $\left(\chi^{2}=206.83, d f=110\right.$, RMSEA $=.03$; CFI $=$ $.98 ; \mathrm{SRMR}=.03, \mathrm{AIC}=49762.87)$ compared to the previous model and was selected as the final model. Figure 2 represents the final model (B) with only the significant paths outlined. Significant non-hypothesized paths are shown in the final model as broken lines.

\section{Effects of Maternal Depressive Symptoms on Mother-child Relationship Quality and Child}

Outcomes Over time. There was a significant direct effect of maternal depressive symptoms at grade 3 on increased experiences of peer victimization in children at grade 5, although these effects were small. There were no significant effects of maternal depressive symptoms on engagement in bullying behaviors at grade 5 or 6 . 
The estimated effects of maternal depressive symptoms at grades 3 and 5 on mother-child relationship quality at grades 5 and 6 were not significant although within-time and betweentime correlations were significant and negative.

\section{Effects of Child Outcomes on Maternal Depressive Symptoms and Mother-child}

Relationship Quality Over time. There was a significant direct effect of bullying behaviors at grade 5 on mother-child relationship quality at grade 6 , in that, engagement in bullying behaviors at grade 5 was associated with decreased reports of mother-child relationship quality grade 6 , controlling for previous time points. Again, this effect was small. No significant effects emerged for peer victimization as an outcome.

\section{Effects of Stress and Protective Factors on Maternal Depressive Symptoms and Parenting}

Over time. A small significant direct effect of marital intimacy at grades 3 and 5 was found to be associated with increased social support at grade 5. In addition, there were small significant direct effects of marital intimacy at grade 5 on increased mother-child relationship quality and decreased depressive symptoms at grade 6 . These significant paths indicate that higher maternal reports of marital intimacy at grades 3 and 5 was associated with increased mother-child relationship quality, and decreased maternal depressive symptoms at grades 5 and 6 as specified.

For social support, there was a small significant direct effect of perceived social support at grade 3 on decreased maternal depressive symptoms at grade 5 only, and increased mother-child relationship quality at grade 6 .

Lastly, there were small significant effects of maternal employment status at grade 3 on decreased maternal depressive symptoms and increased mother-child relationship at grade 5 . There was also a significant indirect effect of employment status at grade 3 on bullying behaviors at grade 6 through mother-child relationship quality at grade 5 . In other words, being employed at grade 3 was positively associated with reports of mother -child relationship at grade 
5, which in turn was negatively associated with engagement in bullying behaviors at grade 6 , controlling for previous time points

Reciprocal Effects. While there was no significant effect of maternal depressive symptoms on mother-child relationship quality overtime, the opposite effect was significant. We found a small significant direct effect of mother-child relationship quality at grades 3 on decreased maternal reports of depressive symptoms at grades 5, suggesting that poorer/lower levels of mother-child relationship quality at grades 3 increased maternal reports of depressive symptoms at grades 5, controlling for previous time point. With respect to reciprocal child related pathways, there was a significant direct effect of engagement in bullying behaviors at grade 5 on decreased mother-child relationship quality at grade 6.

Significant Non-Hypothesized Reciprocal Effects. The estimated non-hypothesized paths were reciprocal paths between the three stress and protective factors, maternal depressive symptoms and mother child-relationship quality across time. The six significant nonhypothesized paths are also shown in the final model (broken lines) with small effects. With regards to stress and support factors, there were small effects of marital intimacy and employment status at grade 3 on increased maternal perceptions of social support at grade 5 . Likewise, employment status at grade 3 and 5 was associated with increased reports of perceived social support at grade 5 and employment status at grade 6.

Maternal depressive symptoms at grade 3 were negatively associated with both marital intimacy and perceived social support at grade 5. Therefore, higher reports of maternal depressive symptoms at grade 3 was associated with lower ratings on perceived marital intimacy and social support at grade 5 . 


\section{Discussion}

This study used longitudinal data to examine the associations of three sets of parent factors maternal depression (a parent functioning variable), parent -child relationship quality (a parenting variable) and marital intimacy, social support and employment status (three stress and support factors) - with child engagement in bullying and experiences of peer victimization behaviors overtime. Specifically, we hypothesized direct positive effects of marital intimacy, employment status and perceived social support on rates of maternal depressive symptoms and mother-child relationship quality over time. Secondly, we expected direct negative effects of maternal reports of depressive symptoms on engagement in bullying and experiences of peer victimization over time. Again, we expected that maternal reports of depressive symptoms would also indirectly and negatively be associated with engagement in bullying and experiences of peer victimization over time through mother-child relationship quality. Lastly, we hypothesized reciprocal relationships among maternal reports of depressive symptoms, mother-child relationship quality, engagement in bullying and experiences of peer victimization over time.

Results showed small direct effects of maternal reports of depressive symptoms on increased experiences of peer victimization behaviors only, and in part support findings by Georgiou [25], who found that maternal reports of depressive symptoms significantly predicted engagement in bullying and experiences of peer victimization compared to children of mothers without depression in a Greek sample. Results from our study did not detect similar direct and significant effects of maternal depressive symptoms at grade 5 on peer victimization or bullying at grade 6 . The non-significant effects may be due to the shorter time lapse between grades 5 and 6 during which data were collected, compared to the two-year period found between grades 3 and 5 . In addition, studies have reported developmental shifts in the types of bullying behaviors and peer victimization experienced with age [61] which may account for current findings. 
Maternal depressive symptoms did not significantly relate to mother-child relationship quality overtime as expected. The average report of maternal depressive symptoms $(\mathrm{M}=8.96-$ 9.08) in this study was lower than the clinical cutoff score (cutoff =16) for maternal depressive symptoms using the Center for Epidemiological Study Depression scale (CES-D; short form) [49], and may account for the non-significant findings of paths from maternal depressive symptoms to mother-child quality. Studies comparing clinical samples to non-clinical samples have however found stronger associations between maternal reports of depressive symptoms and child outcomes via parenting in clinical samples compared to non-clinical samples [24, 28, 29]. Lower depressive symptoms reported by the study sample may also be due to the time period evaluated using the CESD scale, which assesses depressive symptoms in the past week (not currently or within a typical period).

The expected indirect effects of maternal depressive symptoms on bullying and peer victimization through mother-child relationship quality was not significant over time. Motherchild relationship quality, on the other hand, significantly predicted a decrease in bullying behaviors only at later waves but not on bullying behaviors or peer victimization behaviors at earlier waves. First, the significant finding may lend some support in general to other studies that have found similar relationships between some parenting measures and problem behaviors including substance abuse and delinquency $[62,63]$. One speculation of the non-significant findings of similar patterns at earlier time points is that, any possible effects of parent -child relationship quality at grade 3 on child outcomes at grade 5 were lost or weakened by the twoyear time lapse in the data.

Reciprocal effects of child outcomes on parent functioning and parenting were hypothesized based on a recent study that found reciprocal effects between maternal depressive symptoms and child internalizing behaviors $[20,43,44]$. Our study's hypothesis was partly supported for 
bullying behaviors. Current studies report significant bidirectional effects between parental depressive symptoms and conduct behaviors in children [45]. This finding among a non-clinical sample suggests that child engagement in bullying, like other externalizing behaviors, could also predict and/or worsen maternal functioning at a later time, in this case, maternal reports of depressive symptoms.

When the effects of stress and protective factors on maternal factors were examined, increased scores on marital intimacy were associated with increased perceived social support, increased mother-child relationship quality and decreased depressive symptoms at later time points. Increased social support at earlier wavers on the other hand, was associated with increased marital intimacy, decreased depressive symptoms at later time points. These findings are in line with other studies that have examined the role of social support and marital relations such as intimacy on parent functioning and parenting [64, 65].

Lastly, having employment at earlier time points was associated with increased perceived social support, increased mother-child relationship quality and decreased maternal depressive symptoms at a later time point. There was also a small indirect effect of maternal employment at grade 3 on decreased engagement in bullying behaviors at grade 6 via increased mother-child relationship quality at grade 5. There are few studies, offering mixed results, about the role of maternal employment status on involvement in bullying behaviors in particular [66]. These significant findings may be due to majority of the sample being employed at grade $3(r=.75)$. However, guided by socio-cognitive theories, these results are in the expected direction since it is more likely that employment will lead to less stress on parent functioning, which in turn leads to improved parenting and overall mother-relationship quality. It is also interesting that while maternal depression had stronger direct effects on peer victimization over time; maternal employment had indirect effects on engagement in bullying over time, albeit small. This suggests 
that different parent factors may have varying effects on bullying and peer victimization behaviors.

Whereas the effects of maternal depressive symptoms on victimization behaviors may be through maternal non-responsiveness [29], the mechanism for bullying behaviors is not yet clear. In this study like others [25], maternal depressive symptoms did not predict bullying behaviors however; this study further showed that bullying behaviors predicted decreased mother-child relationship quality. This significant effect may be through negative perceptions, subsequent disabling thoughts and emotions parents have about their inability to reduce or control their children's bullying behavior [22, 45]. For mothers with mental health related conditions and other risk factors, such perceptions and negative emotions may exacerbate their condition, communication and relationship skills [25]. With such possible mechanisms associated with experiences of peer victimization and engagement in bullying, multi-pronged parent-child related studies such as this will be important for early child and parent prognosis, effective intervention and prevention research.

\section{Limitations of Study and Future Directions}

Some limitations could be associated with the small effects found in this study. First, the NICHD sample was a low risk sample on the parent functioning (maternal depressive symptoms) and parent practices (mother-child relationship quality) constructs, thus negative effects of these parent factors on bullying behaviors and peer victimization were limited. Secondly, there were limited measures of parent functioning and parenting variables specifically at grades 3, 5 and 6 , thereby restricting the options for examination at these three time points. Future longitudinal studies using clinical samples and including more robust assessment of maternal depression could provide a more accurate picture of the associations of maternal depression, parenting, and children's bullying and victimization. 
Thirdly, the NICHD measures of engagement in bullying and peer victimization had four items each, with single items examining physical, verbal and relational bullying and victimization. Future studies should consider using multi-item measures that offer the opportunity to examine how parent factors are associated with both traditional (physical, verbal, relational) and cyber bullying, and peer victimization. Also, the increasing evidence of long term negative impact of bully-victim behaviors (i.e., behaviors of individuals who are victimized and later become bullies) later in young adulthood compared to victimized peers $[1,5]$, suggests that related questions should be included in parent-child studies in order to gain further insight into potential parent effects on bully-victim behaviors as well.

As a fourth point, future studies should include multiple reporters of parent and child measures. For example, both maternal and child reports on parent-child relationship quality and instead of only maternal reports may strengthen effects of findings. Likewise, parent, teacher and/peer reports of bullying and peer victimization instead of only child reports would bolster findings. Notably, fewer studies have parents and teacher reports because they are least likely to observe or acknowledge these behaviors compared to peers. Proxy measures, however, such as parent and teacher reports on aggression, deviance and changes in academic achievement may be measures that provide substantive correlations with self-reported accounts of bullying and peer victimization [5].

This research examined parent factors related to engagement in bullying and peer victimization of children within grades 3 to 6 . Researchers should also examine the three dimensions of parent factors at younger ages of children to see if there are differences in strength of parent effects. First, considering that generally, the impact of parents' influence on children's behaviors reduces as they grow and peer influences increase, it is also possible that the effects of parent factors on these child outcomes begin early, and these effects will be stronger than effects 
at $3^{\text {rd }}$ grade. In other words, the foundation is set early for future bullying and related behaviors among peers. There is evidence of parent functioning such as low maternal empathy being positively related to bullying behaviors in preschoolers [67]. Therefore, examinations of early parent functioning and parenting may help us understand the process, and changes in strength of effects of parent factors over time on these child outcomes. There is evidence that early parent functioning and parenting is associated with antisocial and conduct behaviors in early childhood [68] thus this idea is worth exploring for bullying and related behaviors too.

\section{Summary}

This study is one of very few studies that have examined the transactional role of parent factors in bullying and peer victimization in a US sample, a major gap in the field of peer victimization/bullying research. Three waves of longitudinal data from the NICHD Study of Early Child Care and Youth Development were used to test the direct, indirect and reciprocal effects of maternal depressive symptoms, stress/support factors on bullying and peer victimization behaviors through mother-child relationship quality. Findings from this study revealed small significant effects of the role of maternal depressive symptoms and mother-child relationship quality on engagement in bullying and peer victimization. Furthermore, maternal employment status at an early time point showed small negative indirect effects on bullying behaviors later through the parenting process (mother-child relationship quality). Despite small significant effects, the study provides empirical information to support the idea that different parent factors may have deferential effects on bullying behaviors and peer victimization. Also, considering that these significant effects were found in this non-clinical sample, which had below average scores in maternal depressive symptoms, and overall healthy reports of motherchild relationship quality, bigger effects may be expected to be found in high-risk families, which should be a focus of future investigations. 


\section{References}

1. Copeland WE, Wolke D, Angold A, Costello EJ (2013) Adult Psychiatric Outcomes of Bullying and Being Bullied by Peers in Childhood and Adolescence Psychiatric Outcomes of Bullying and Being Bullied. JAMA Psychiatry, 70(4), 419-426.

2. Kim MJ, Catalano RF, Haggerty KP, Abbott RD (2011) Bullying at elementary school and problem behaviour in young adulthood: A study of bullying, violence and substance use $\backslash$ from age 11 to age 21. Crim Behav Ment Health, 21(2), 136-144.

3. Niemelä S, Brunstein-Klomek A, Sillanmäki, L, Helenius H, Piha, J, Kumpulainen K, Moilanen I, Tamminen T, Almqvist F, Sourander A (2011) Childhood bullying behaviors at age eight and substance use at age 18 among males. A nationwide prospective study. Addict Behav, 36(3), 256-260.

4. Takizawa R, Maughan B, Arseneault L (2014) Adult health outcomes of childhood bullying victimization: evidence from a five-decade longitudinal British birth cohort. Am J Psychiatry, 171(7), 777-784.

5. Arseneault L, Walsh E, Trzesniewski K, Newcombe R, Caspi A, Moffitt TE (2006) Bullying victimization uniquely contributes to adjustment problems in young children: a nationally representative cohort study. Pediatrics, 118, 1, 130-138.

6. National Center for Education Statistics (NCES, 2011) Report of the Percentage of students, ages 12-18 who reported being bullied at school and the frequency of being bullied, by selected student and school characteristics: School year 2006-07.

7. Nishioka V, Coe M, Burke A, Hanita, M, Sprague J (2011) Student-reported overt And relational aggression and victimization in grades 3-8. (Issues \& Answers Report, REL 2011-No. 114). Washington, DC: U.S.

8. Wang J, Iannotti RJ, Nansel TR (2009) School bullying among adolescents in the United 
States: Physical, verbal, relational, and cyber. J Adolesc Health, 45, 368-375.

9. Zhang A, Musu-Gillette L, Oudekerk BA (2016) Indicators of School Crime and Safety: 2015. NCES 2016-079. NCJ 249758. National Center for Education Statistics.

10. Espelage DL (2014) Ecological theory: Preventing youth bullying, aggression, and victimization. Theory Pract, 53(4), 257-264.

11. Hong JS, \& Espelage DL (2012) A review of research on bullying and peer victimization in school: An ecological system analysis. Aggress Violent Behav, 17(4), 311-322.

12. Bandura A (2006) Guide for constructing self-efficacy scales. Self-efficacy beliefs of adolescents, Chapter 14, 307-337.

13. Bronfenbrenner U, Morris PA (2006) The bioecological model of human development. Handbook Child Psychol.

14. Malm EK, Henrich C, Varjas K Meyers J (2016) Parental self-efficacy and bullying. In elementary school. J Sch Violence, 16, 411-425.

15. Belsky J (1984) The determinants of parenting: A process model. Child Dev, 55, 83-96.

16. Sameroff A (2009) The transactional model. American Psychological Association.

17. Barker ED, Jaffee SR, Uher R, Maughan B (2011) The contribution of prenatal and postnatal maternal anxiety and depression to child maladjustment. Depress Anxiety, 28(8),696-702

18. Benton PM, Skouteris H, Hayden M (2015) Does maternal psychopathology increase the risk of preschooler obesity? A systematic review. Appetite, 87,259-282.

19. Duarte CS, Shen S, Wu P, Must A (2012) Maternal depression and child BMI: longitudinal findings from a US sample. Pediatr Obes, 7(2), 124-133.

20. Goodman SH, Rouse MH, Connell AM, Broth MR, Hall CM, Heyward D (2011) Maternal depression and child psychopathology: A meta-analytic review. Clin Child Fam Psychol Rev, 14, 1, 1-27. 
PARENTS \& PEER VICTIMIZATION

21. Lamis DA, Malone PS, Lansford JE, Lochman JE (2012) Maternal depressive symptoms as a predictor of alcohol use onset and heavy episodic drinking in youths. J Consult Clin Psychol, 80(5), 887.

22. Leckman-Westin E, Cohen PR, Stueve A (2009) Maternal depression and mother-child interaction patterns: Association with toddler problems and continuity of effects to late childhood. J Child Psychol Psychiatry, 50(9), 1176-1184.

23. Murray L, Arteche A, Fearon P, Halligan S, Goodyer I, Cooper P (2011) Maternal postnatal depression and the development of depression in offspring up to 16 years of age. $\mathrm{J}$ Am Acad Child Adolesc Psychiatry, 50(5), 460-470.

24. Weissman MM, Wickramaratne P, Gameroff MJ, Warner V, Pilowsky D, Kohad R G, Verdeli H, Skipper J, Talati A (2016) Offspring of depressed parents: 30 years later. Am J of Psychiatry, 173(10), 1024-1032.

25. Georgiou SN (2008) Bullying and victimization at school: The role of mothers. Br J Educ Psychol, 78, 109-125.

26. Brennan PA, Le Brocque R, Hammen C (2003) Maternal depression, parent-child relationships, and resilient outcomes in adolescence. J Am Acad Child Adolesc Psychiatry, 42, 12, 1469-1477.

27. Eiden RD, Colder C, Edwards EP, Leonard KE (2009) A longitudinal study of social competence among children of alcoholic and nonalcoholic parents: Role of parental psychopathology, parental warmth, and self-regulation. Psychol Addict Behav, 23(1), 36.

28. Gelfand DM, Teti DM (1990) The effects of maternal depression on children. Clin Psychol Rev, 10, 3, 329-353.

29. Goodman SH, Tully E (2008) Children of depressed mothers. Handbook of Depression In Children and Adolescents, 415-440. 
30. Keijsers L, Poulin F (2013) Developmental changes in parent-child communication throughout adolescence. Dev Psychol, 49(12), 2301.

31. Monks CP, Smith PK, Naylor P, Barter C, Ireland JL, Coyne I (2009) Bullying In different contexts: Commonalities, differences and the role of theory. Aggress Violent Behav, 14, $146-156$.

32. Laursen B, Collins WA (2009) Parent — child relationships during adolescence. Handbook of Adolescent Psychology, Chapter 4.

33. Kim J, Thompson EA, Walsh EM, Schepp KG (2015) Trajectories of Parent-Adolescent Relationship Quality Among At-Risk Youth: Parental Depression and Adolescent Developmental Outcomes. Arch Psychiatr Nurs, 29(6), 434-440.

34. Conger RD, Rueter MA, Elder, GH (1999) Couple resilience to economic pressure. J Pers Soc Psychol, 76, 54-71.

35. Hanington L, Heron J, Stein A, Ramchandani P (2012) Parental depression and child outcomes-is marital conflict the missing link?. Child Care Health Dev, 38(4), 520-529.

36. Low SM, Stocker C (2005) Family functioning and children's adjustment: associations among parents' depressed mood, marital hostility, parent-child hostility, and children's adjustment. J Fam Psychol, 19(3), 394.

37. Lee CYS, Anderson JR, Horowitz JL, August GJ (2009) Family income and parenting: The role of parental depression and social support. Fam Relat, 58(4), 417-430.

38. Suzuki S, Holloway SD, Yamamoto Y, Mindnich JD (2009) Parenting self-efficacy and social support in Japan and the United States. J Fam Issues, 30(11), 1505-1526.

39. Mayer SE (2010) Revisiting an old question: How much does parental income affect child outcomes? Focus, 27, 2, 21-26.

40. Newland RP, Crnic KA, Cox MJ, Mills-Koonce WR (2013) The family model stress and 
maternal psychological symptoms: mediated pathways from economic hardship to parenting. J Fam Psychol, 27(1), 96.

41. Baldry AC (2003) Bullying in schools and exposure to domestic violence. Child Abuse Negl, $27,713-732$.

42. Bowes L, Arseneault L, Maughan B, Taylor A, Caspi A, Moffitt TE (2009) School, neighborhood, and family factors are associated with children's bullying involvement: A nationally representative longitudinal study. J Am Acad Child Adolesc Psychiatry, 48, 5, $545-553$.

43. Bagner DM, Pettit JW, Lewinsohn PM, Seeley JR, Jaccard J (2013) Disentangling the temporal relationship between parental depressive symptoms and early child behavior problems: A transactional framework. J Clin Child Adolesc Psychol, 42(1), 78-90.

44. Heinz AL (2016) Kids Can Screw Up Their Parents, Too: An Analysis of the Reciprocal Influences Between Maternal Depressive Symptoms and Child Problem Behaviors From Child Age 2 to 15 (Doctoral dissertation, Columbia University).

45. Gross HE, Shaw DS, Moilanen KL (2008) Reciprocal associations between boys' externalizing problems and mothers' depressive symptoms. J of Abnorm Child Psychol, 36(5), 693-709.

46. Georgiou SN, Fanti KA (2010) A transactional model of bullying and victimization. Soc Psychol Educ, 13(3), 295-311.

47. Fanti KA, Georgiou S (2012) Bullies and Their Mothers: Who Influence Whom? Int J Soc Beh Educ Econ Bus Ind Eng, 6(6), 1215-1221.

48. National Institute of Early Child Development- Early Child Care Research Network (NICHD ECCRN) (Ed.) (2005) Child care and child development: Results of the NICHD study of early child care and youth development. New York: Guilford 
PARENTS \& PEER VICTIMIZATION

49. Radloff LS (1977) The CES-D scale A self-report depression scale for research in the general population. Appl Psychol Meas, 1, 3, 385-401.

50. Lewinsohn PM, Seeley JR, Roberts RE, Allen NB (1997) Center for Epidemiologic Studies Depression Scale (CES-D) as a screening instrument for depression among communityresiding older adults. Psychol Aging, 12(2), 277.

51. Driscoll KC, Pianta RC (2010) Banking Time in Head Start: Early efficacy of an intervention designed to promote supportive teacher-child relationships. Early Educ Dev, 21, 38-64.

52. Schaefer M T, Olson, DH (1981) Assessing intimacy: The pair inventory. J Marital Fam Ther, 7(1), 47-60.

53. Moore KA, McCabe MP, Stockdale JE (1998) Factor analysis of the Personal Assessment of Intimacy In Relationships Scale (PAIR): Engagement, communication and shared friendships. J Sex Marital Ther, 13, 361-368.

54. Ladd, G. W., Kochenderfer, B. J., \& Coleman, C. C. (1997). Classroom peer acceptance, friendship, and victimization: Destinct relation systems that contribute uniquely to children's school adjustment?. Child development, 68(6), 1181-1197.

55. Yoleri S, Gürşimşek AI (2012) Temperamental Characteristics and peer victimization among pre-school children. Int J of Global Educ, 1, 1, 54-65.

56. Rothbart MK, Ahadi SA, Hershey KL, Fisher P (2001) Investigations of temperament at three to seven years:The Children's Behavior Questionnaire. Child Dev, 72, 5,1394-1408.

57. Cole DA, Maxwell SE (2003) Testing meditational models with longitudinal data: Questions and tips in the use of structural equation modeling. J Abnorm Psychol, 112, 558-577.

58. Muthén LK, Muthén B (2010) Mplus user's guide, 6th. Los Angeles, CA: Muthén \&Muthén. 59. Kline RB (2011) Principles and practice of structural equation modeling. ( $\left.3^{\text {rd }} \mathrm{Ed}\right)$. Guilford 60. Asparouhov T, Muthén B (2010) Weighted least squares estimation with missing data. Mplus 
Technical Appendix, 1-10.

61. Varjas K, Henrich CC, Meyers J (2009). Urban middle school students' perceptions Of bullying, cyberbullying, and school safety. J Sch Violence, 8(2), 159-176.

62. Fletcher AC, Steinberg L, Williams-Wheeler M (2004) Parental influences on adolescent Problem behavior: Revisiting Stattin and Kerr. Child Dev, 75, 3, 781-796.

63. Pettit GS, Bates JE, Dodge KA, Meece DW (1999) The Impact of After-School Peer Contact on Early Adolescent Externalizing Problems Is Moderated by Parental Monitoring, Perceived Neighborhood Safety, and Prior Adjustment. Child Dev, 70, 3, 768-778.

64. Manuel JI, Martinson ML, Bledsoe-Mansori SE, Bellamy JL (2012) The influence of Stress and social support on depressive symptoms in mothers with young children. Soc Sci Med, 75(11), 2013-20.

65. Taraban L, Shaw DS, Leve LD, Wilson MN, Dishion TJ, Natsuaki MN, ... Reiss D (2017) Maternal depression and parenting in early childhood: Contextual influence of marital quality and social support in two samples. Dev Psychol, 53(3), 436.

66. Christie-Mizell CA, Keil JM, Laske MT, Stewart J (2011) Bullying Behavior, Parents’ Work Hours and Early Adolescents' Perceptions of Time Spent with Parents. Youth Soc, 43(4), $1570-1595$.

67. Curtner-Smith ME, Culp AM, Culp R, Scheib C, Owen K, Tilley A et al. (2006) Mothers' parenting and young economically disadvantaged children's relational and overt bullying. J Child Fam Stud, 15(2), 177-189.

68. Lansford JE, Criss MM, Laird RD, Shaw DS, Pettit GS, Bates JE, Dodge K (2011) Reciprocal relations between parents' physical discipline and children's externalizing behavior during Middle childhood and adolescence. Dev Psychopathol, 23, 1, 225-238. 